\title{
Patient characteristics and frequency of bodily distress syndrome in primary care:
}

\author{
a cross-sectional study
}

\begin{abstract}
\section{Background}

Bodily distress syndrome (BDS) is a newly proposed diagnosis of medically unexplained symptoms, which is based on empirical research in primary care.
\end{abstract}

\section{Aim}

To estimate the frequency of BDS in primary care and describe the characteristics of patients with BDS.

\section{Design and setting}

A cross-sectional study of primary care patients in urban and rural areas of Central Denmark Region.

\section{Method}

Data were obtained from GP one-page registration forms, patient questionnaires (including a checklist for BDS), and national registers.

\section{Results}

A total of 1356 primary care patients were included, of whom 230 patients $117.0 \%, 95 \%$ confidence intervals $[\mathrm{CI}]=15.0$ to 19.1$)$ fulfilled the BDS criteria. BDS was more common among primary care patients aged $41-65$ years (odds ratio $[\mathrm{OR}]=1.9,95 \% \mathrm{Cl}=1.3$ to 3.0 ) and was equally frequent among males and females (female sex, OR $0.9,95 \% \mathrm{Cl}=0.6$ to 1.3). Patients with BDS were characterised by poor health-related quality of life (HRQOL) on the 12-item Short-Form Health Survey, that is, physical component summary scores $<40$ (OR 20.5, 95\% Cl $=12.9$ to 32.4 ) and mental component summary scores $<40$ (OR 3.5 , $95 \% \mathrm{Cl}=2.2$ to 5.6 ). Furthermore, patients with BDS were more likely to have high scores on the Symptom Checklist for anxiety (OR 2.2. $95 \% \mathrm{Cl}=1.4$ to 3.4 ) and depression (OR 5.1, $95 \% \mathrm{Cl}=3.3$ to 7.9 , but regression analyses showed that mental morbidity did not account for the poor HRQOL.

\section{Conclusion}

BDS is common among primary care patients, and patients with BDS have a higher probability of poor HRQOL and mental health problems.

\section{Keywords}

cross-sectional analysis; general practice; signs and symptoms; somatoform disorders.

\section{INTRODUCTION}

GPs play a key role in the detection and management of medically unexplained symptoms (MUS), ' but the lack of appropriate and accurate diagnostic standards that can identify and delimit moderate-to-severe MUS, or functional disorders, hampers optimal patient management. ${ }^{2-4}$ Bodily distress syndrome (BDS) is a newlyproposed diagnosis of functional disorders. BDS has certain advantages compared with existing labels: it is based on empirical research, $3,5,6$ it provides needed explanatory models, ${ }^{7}$ and, as it is an overarching diagnosis, it may replace the numerous overlapping categories of functional somatic syndromes and somatoform disorders that tend to challenge a GP's decision when selecting the most suitable diagnosis for a patient.

BDS is defined by specific physical symptom patterns ${ }^{6}$ comprising four main groups: cardiopulmonary, gastrointestinal, musculoskeletal, and general symptoms. ${ }^{3}$ In recent years, BDS has proven useful as a clinical and research diagnosis of functional disorders in specialised settings. ${ }^{8}$ The BDS criteria have been included in the current draft of the World Health Organization's International Classification of Diseases, 11th revision (ICD-11), although they are still the subject of debate. ${ }^{7}$ As epidemiological knowledge of BDS in primary care is lacking, this study aimed to estimate the

A Budtz-Lilly, MD, PhD student; M Vestergaard MD, PhD, professor; AH Carlsen, MSc,

statistician; M Rosendal, MD, PhD, senior researcher, Research Unit for General Practice, Department of Public Health, Aarhus University, Denmark. P Fink, MD, PhD, DMSc, director, Research Clinic for Functional Disorders and Psychosomatics, Aarhus University Hospital, Denmark.

Address for correspondence

Anna Budtz-Lilly, Research Unit for General frequency and describe the characteristics of patients fulfilling the BDS criteria in general practice.

\section{METHOD}

\section{Design and setting}

A cross-sectional study was performed with primary care patients in the Central Denmark Region, which has a population of 1250000 inhabitants, based on data from one-page forms completed by GPs, patient questionnaires, and nationwide registries.

\section{Study participants}

All GPs in the Central Denmark Region were invited to participate in the study. Participating and non-participating GPs did not differ with regard to type of practice, whereas more female GPs and fewer GPs with $>20$ years of practice experience participated. Age and sex distributions were comparable between patients listed with participating and non-participating GPs. The 388 (44.5\%) participating GPs registered all patient contacts during one randomly assigned day on one-page forms including information on any chronic disease and the main diagnosis of the index consultation. All diagnoses were coded and categorised according to the International Classification of Primary Care, 2nd edition (ICPC-2-R)..${ }^{9.10}$ After the consultation, a questionnaire was sent to all identifiable patients aged $\geq 18$ years who had completed a health-

Practice, Department of Public Health, Aarhus University, Bartholins Allé 2, 8000 Aarhus C, Denmark.

E-mail: anna.budtz-lillyafeap.dk

Submitted: 26 January 2015; Editor's response: 20 March 2015; final acceptance: 18 May 2015. CBritish Journal of General Practice

This is the full-length article (published online 1 Sep 2015) of an abridged version published in print. Cite this article as: Br J Gen Pract 2015; DOI: 10.3399/bjgp15X686545 


\section{How this fits in}

GPs play a key role in the detection of medically unexplained symptoms (MUS), but lack accurate diagnostic standards. Bodily distress syndrome (BDS) is a newly proposed diagnosis specifically for moderate-to-severe MUS; that is, functional disorders. This study found that BDS is common among patients in primary care, and that patients with BDS have a higher probability of poor healthrelated quality of life (HRQOL) and mental health problems. The results support the potential usefulness of BDS as a clinical diagnosis, and the BDS criteria may provide an improved basis for future therapeutic trials and epidemiological studies in primary care.

related consultation with their GP (Figure 1). The study population has previously been described in detail. ${ }^{5}$

\section{Data collection and included variables}

Data on BDS status were obtained from patient questionnaires, that is, the BDS checklist (Appendix 1). A previous validation of the BDS checklist showed that four symptoms from one or more of the BDS symptom groups indicated probable BDS. 5
Figure 1. Flowchart of participating GPs and patients in the bodily distress syndrome (BDS) study.
The diagnostic criteria for BDS used in this study are shown in Box 1. Information on self-perceived health was obtained from the mental component summary (MCS) score and the physical component summary (PCS) score of the 12-item Short-Form Health Survey, Version 1 (SF-12)."1 Scores for anxiety and depression were obtained from the Symptom Checklist (SCL). ${ }^{12}$ On the SCL, anxiety and depression subscales with sum scores of $\geq 5$ indicated probable anxiety or depression. ${ }^{12,13} \mathrm{~A}$ question was included that addressed patient-perceived longterm physical illness ( $>3$ months within the last 12 months). The questionnaires were processed using TeleForm (version 8.0).

All Danish citizens are registered in the Danish Civil Registration System, ${ }^{14}$ with a unique personal identification number, which was used to link each primary care patient accurately to the national registries. From Statistics Denmark, ${ }^{15}$ data were obtained on patient socioeconomic status. The Danish National Prescription Registry provided data regarding use of prescription medication sold in any Danish pharmacy. ${ }^{16}$ Data were obtained on the use of proton pump inhibitors (PPI) (Anatomical Therapeutic Chemical [ACT]: A02BC) and opioids (ATC: N02A) for the entire year preceding the index consultation. The Danish National Patient Register and the Danish Psychiatric Central Research Register provided data on hospital admissions and outpatient contacts as these two registers hold this information for all patients in Danish hospitals. ${ }^{17,18}$ Likewise, numbers of inpatient and outpatient admissions to both general and psychiatric hospitals were obtained. Finally, from the Danish National Health Service Register, which holds information on all patient contacts with primary healthcare providers, ${ }^{19}$ data were obtained on face-to-face contacts during the year preceding the index consultation for all included patients. In the case of general practice, physiotherapists, chiropractors, and/or specialised outpatient clinics, it was estimated whether a patient had at least one face-to-face consultation and whether a patient was among the top 10 attenders; that is, among the $10 \%$ of patients who most frequently contacted these services. In the case of inpatient hospital admissions, it was estimated whether the patient had at least one admission.

Pregnant women were excluded from the analyses. Patients for whom the BDS algorithm could not be conducted were also excluded. These were patients with missing information on the BDS checklist; patients with missing information regarding 
the disability criterion (that is, the general health item of SF-12); and patients for whom differential diagnoses could not be ruled out lthat is, patients who received a relevant differential diagnosis other than BDS at the index consultation), and patients with GP-registered chronic physical disease. ${ }^{13}$

Additional analyses were performed on a population consisting of all responders irrespective of comorbidity to examine how these exclusion criteria would affect the result.

\section{Statistics}

Descriptive analyses were performed for all participants and for BDS-positive and BDS-negative patients separately. Categorical data are presented as numbers and percentages, that is, $95 \%$ confidence intervals (Cls), while normally distributed continuous data are presented as means, standard deviations (SD), and ranges. The association between BDS and selected patient characteristics was assessed using a logistic regression model.

Crude analyses were performed in addition to a model adjusting for age, sex, education level, marital status, labour market status, depression, and anxiety. Data were analysed using Stata (version 13.0).

\section{RESULTS}

The 388 participating GPs had 4967 face-toface consultations during the study period. A total of 325 patients were excluded because

\section{Box 1. Diagnostic criteria for bodily distress syndrome}

1. During the last 4 weeks, ${ }^{a}$ the patient has suffered from at least four symptoms ${ }^{b}$ from one or more of the following groups: ${ }^{c}$

Cardiopulmonary/autonomic arousal

Palpitations/heart pounding, precordial discomfort, breathlessness without exertion, hyperventilation, hot or cold sweats, dry mouth

Gastrointestinal arousal

Abdominal pains, frequent loose bowel movements, feeling bloated/full of gas/distended, regurgitations, diarrhoea, nausea, burning sensation in chest or epigastrium

\section{Musculoskeletal tension}

Pains in arms or legs, muscular aches or pains, pains in the joints, feelings of paresis or localised weakness, backache, pain moving from one place to another, unpleasant numbness or tingling sensations

\section{General symptoms}

Concentration difficulties, impairment of memory, excessive fatigue, headache, dizziness

\section{Relevant differential diagnoses have been ruled out, for example, chronic physical disease or other} differential diagnosis at index consultation.

3. The patient has been disabled by the symptoms, that is, fair or poor health according to the SF-12 global health item.

a Short time frame to reduce the risk of recall bias. ${ }^{b}$ Results are based on a bodily distress syndrome questionnaire validation study. "Symptom groups are based on empiric results from a large sample of patients from primary care and medical departments. of missing information on patient identity and five because of late dropout; 475 patients were registered with an address that was either unknown or protected from research. Thus, a questionnaire was sent to 4162 patients. The questionnaire was completed and returned by 2475 patients (response rate 59\%) (Figure 1). After excluding study participants who were pregnant, had chronic diseases, or had insufficient data to perform the BDS algorithm, 1356 patients (mean age $=48.9$ years, $S D=16.6$, range $=18-95$ years) remained for the analyses, of whom 230 patients $117.0 \%$, $95 \% \mathrm{Cl}=15.0$ to 19.1 ) fulfilled the criteria for BDS (Figure 1).

Non-participating patients were more likely to be young, to be living alone, to have fewer years of education, and to be unemployed than participating patients, while the sex distribution was comparable between non-participants and participants (data not shown).

Patients with BDS had poorer selfperceived mental health than patients without BDS, with an average MCS score of 39.1 (SD = 11.2) versus 50.0 (SD =9.0), and also had poorer physical health, with an average PCS score of 33.6 (SD = 10.1) versus $50.6 \quad(S D=8.6)$. In the present study, BDS was equally frequent among males and females (female sex, OR 0.9, $95 \% \mathrm{Cl}=0.6$ to 1.3$)$. BDS was more common among patients aged 41-65 years IOR 1.9, $95 \% \mathrm{Cl}=1.3$ to 3.0 ), patients with $<10$ years of education (OR 1.9, 95\% Cl=1.3 to 3.0 ), patients who were unemployed IOR 5.3, $95 \% \mathrm{Cl}=2.8$ to 9.9 ), and patients receiving disability pension (OR 8.7, $95 \% \mathrm{Cl}=4.7$ to 16.1). Patients with BDS were more likely to have self-perceived long-term physical illness (OR 6.8, 95\% Cl = 4.7 to 9.9) and high SCL scores for anxiety IOR 2.2, 95\% Cl = 1.4 to 3.4 ) and depression (OR 5.1, 95\% Cl = 3.3 to 7.9). Furthermore, patients with BDS were more likely to receive pharmacological treatment with opioids (OR 3.6, 95\% Cl = 2.2 to 5.7) and PPls (OR 2.1, 95\% Cl=1.3 to 3.3). They also had a higher use of medical services in all types of health care, particularly in general practice IOR 4.3, $95 \% \mathrm{Cl}=1.4$ to 13.0 ) (Table 1 ).

To examine how the exclusion of patients with GP-reported chronic physical disease would affect the results, additional analyses were performed on the population of all responders irrespective of comorbidity ( $n=2475)$. Compared with the population included in the main analyses, this population had a higher mean age of 54.3 years $(S D=17.5)$, and a larger proportion of patients presented with a 
symptom pattern corresponding with BDS (23.8\%, $95 \% \mathrm{Cl}=22.1$ to 25.6). These BDSpositive patients had slightly better mental health, slightly poorer physical health, and a higher use of PPI than the BDS-positive patients in the main analyses (data not shown, results statistically significant).

\section{Table 1. Primary care population characteristics and associations between bodily distress syndrome and selected variables}

\begin{tabular}{|c|c|c|c|c|c|c|}
\hline & Participants, $n$ & $\mathrm{BDS}+, n$ & $\%$ & COR & $\mathrm{AOR}^{\mathrm{a}}$ & $95 \% \mathrm{Cl}$ \\
\hline Overall & 1356 & 230 & 17.0 & & & \\
\hline \multicolumn{7}{|l|}{ Sociodemographic status } \\
\hline \multicolumn{7}{|l|}{ Age, years } \\
\hline $18-40$ & 438 & 60 & 13.7 & 1.0 & 1.0 & Ref \\
\hline $41-65$ & 684 & 139 & 20.9 & 1.6 & 1.9 & 1.3 to 3.0 \\
\hline$>65$ & 234 & 31 & 13.2 & 1.0 & 1.5 & 0.6 to 3.7 \\
\hline \multicolumn{7}{|l|}{ Sex } \\
\hline Male & 482 & 67 & 13.9 & 1.0 & 1.0 & Ref \\
\hline Female & 874 & 163 & 18.6 & 1.4 & 0.9 & 0.6 to 1.3 \\
\hline \multicolumn{7}{|l|}{ Marital status } \\
\hline Cohabiting & 1024 & 167 & 16.3 & 1.0 & 1.0 & Ref \\
\hline Living alone & 330 & 63 & 19.1 & 1.2 & 0.7 & 0.4 to 1.0 \\
\hline \multicolumn{7}{|l|}{ Education, years } \\
\hline$>15$ & 285 & 40 & 14.0 & 1.0 & 1.0 & Ref \\
\hline $10-15$ & 681 & 95 & 14.0 & 1.0 & 1.0 & 0.6 to 1.5 \\
\hline$<10$ & 361 & 86 & 23.8 & 1.9 & 1.9 & 1.3 to 3.0 \\
\hline \multicolumn{7}{|l|}{ Labour market affiliation } \\
\hline Working & 880 & 115 & 13.1 & 1.0 & 1.0 & Ref \\
\hline Student & 65 & 6 & 9.2 & 0.7 & 0.7 & 0.3 to 1.8 \\
\hline Unemployed & 66 & 33 & 50.0 & 6.7 & 5.3 & 2.8 to 9.9 \\
\hline Retirement pension & 277 & 38 & 13.7 & 1.1 & 1.1 & 0.5 to 2.3 \\
\hline Partial/full disability pension & 66 & 38 & 57.6 & 9.0 & 8.7 & 4.7 to 16.1 \\
\hline \multicolumn{7}{|l|}{ Self-reported health status } \\
\hline Physical health: SF-12, ${ }^{\text {b PCS }<40}$ & 314 & 161 & 51.3 & 17.6 & 20.5 & 12.9 to 32.4 \\
\hline 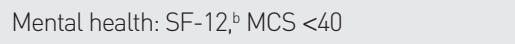 & 265 & 118 & 44.5 & 7.6 & 3.5 & 2.2 to 5.6 \\
\hline Anxiety: SCL-4 $\geq 5$ & 272 & 111 & 40.8 & 5.6 & 2.2 & 1.4 to 3.4 \\
\hline Depression: SCL-6 $\geq 5$ & 318 & 133 & 41.8 & 7.1 & 5.1 & 3.3 to 7.9 \\
\hline Patient-perceived long-term physical illness ${ }^{c}$ & 278 & 128 & 46.4 & 8.4 & 6.8 & 4.7 to 9.9 \\
\hline \multicolumn{7}{|l|}{ Drug treatment } \\
\hline Opioids & 132 & 52 & 39.4 & 3.8 & 3.6 & 2.2 to 5.7 \\
\hline Proton pump inhibitors & 160 & 50 & 31.3 & 2.6 & 2.1 & 1.3 to 3.3 \\
\hline \multicolumn{7}{|l|}{ Healthcare use } \\
\hline General practice & 1274 & 226 & 17.7 & 4.2 & 4.3 & 1.4 to 13.0 \\
\hline General practice top $10 \%$ attenders $^{d}$ & 123 & 61 & 49.6 & 6.2 & 4.1 & 2.5 to 6.6 \\
\hline Specialised outpatient clinics & 672 & 154 & 23.0 & 2.4 & 2.4 & 1.7 to 3.4 \\
\hline Specialised outpatient clinics top $10 \%$ attenders ${ }^{e}$ & 118 & 44 & 37.3 & 3.4 & 3.1 & 1.9 to 5.1 \\
\hline Physiotherapists/chiropractors & 316 & 76 & 24.3 & 1.8 & 1.7 & 1.2 to 2.4 \\
\hline $\begin{array}{l}\text { Physiotherapists and chiropractors top } \\
10 \% \text { attenders }\end{array}$ & 123 & 34 & 27.6 & 2.0 & 1.7 & 1.0 to 2.9 \\
\hline Hospital admissions/inpatient clinics & 179 & 53 & 29.6 & 2.4 & 2.1 & 1.3 to 3.3 \\
\hline
\end{tabular}

No variable had more than $2.1 \%$ missing data, apart from the MCS and PCS scales, which had $6.9 \%$ missing data. ${ }^{a}$ Age, sex, education, marital status, labour market status, depression, and anxiety. ${ }^{b}$ Summary scores estimated using US scoring algorithms. "Item text: 'During the latest 12 months, have you been ill for a long term Ithat is, $>3$ months)?: ' $>12$ contacts the year preceding the index consultation. ${ }^{e}>5$ contacts the year preceding the index consultation. ${ }^{f}>8$ contacts the year preceding the index consultation. $A O R=$ adjusted odds ratio. BDS = bodily distress syndrome. $C O R=$ crude odd ratio. $M C S=$ mental component summary. $P C S=$ physical component summary. Ref $=$ reference. $S C L=$ Symptom Checklist. SF-12 = 12-item Short-Form Health Survey.

\section{DISCUSSION}

\section{Summary}

BDS was found to be common in primary care for both males and females (frequency $=17 \%$ ). BDS is particularly common among patients aged 41-65 years, people with impaired mental and physical health status, and patients with limited socioeconomic resources. Patients with BDS had high comorbidity with depression and anxiety, although mental morbidity did not account for their poor health-related quality of life.

\section{Strengths and limitations}

Although all consecutive patients who consulted their GP on the assigned days were contacted, $40 \%$ of the patients who received a questionnaire did not respond. The sex distribution was comparable between participants and non-participants, while non-participating patients were younger and had more limited socioeconomic resources than participating patients. It is not known how these latter differences may have affected the estimates of BDS frequency; that is, fewer young participating patients may have caused an overestimation, while fewer participating patients with limited socioeconomic resources may have caused an underestimation.

In the absence of clinical assessment by a physician, which is required for making a clinical diagnosis, patients with GP-reported chronic physical diseases were excluded from the main analyses. This may have improved the specificity, but may also have led to an underestimation of the BDS frequency because a patient with a GP-reported physical disease could also have BDS. Instead of using the global health item of the SF-12, the authors recommend inclusion of specific items focusing on functional impairment ffor example, selected items from the World Health Organization Disability Assessment Schedulel in the BDS checklist in future studies. In this way, more valid estimates could be made of the functional impairment resulting from the specific symptom patterns. Nevertheless, the algorithm for case identification used in this study appears suitable for defining a large patient population in need of health care.

Previously translated and validated scales were used, and the questionnaires were pilot tested among primary care patients. In combination with the highquality register data, this should reduce the risk of information bias.

Physical symptoms are common in 
anxiety and depression disorders. ${ }^{20}$ By adjusting for these mental disorders in the regression model, it was possible to examine whether the physical symptoms were associated with depression, anxiety, or BDS. The study found that BDS was still markedly associated with impaired health, although attenuated, in the adjusted analyses. However, the cross-sectional nature of the study means it is not possible to make any causal interpretation between BDS, anxiety, and depression.

Finally, the results apply only to primary care waiting-room patients; BDS characteristics remain to be investigated in other population groups; for example, the general population or patients in general hospital settings.

\section{Funding}

The study was funded by the Health Research Fund of the Central Denmark Region (reference 1-45-72-4-09), the Committee for Quality Improvement and Continuing Medical Education in the Central Denmark Region (reference 1-30-72-270-08), the Danish foundation TrygFonden (reference 7-12-0759), and the Lundbeck Foundation (reference 1R1552012-11280). The funding sources had no role in this study, including study design, data collection, data analyses, writing of the manuscript, or publication decisions.

\section{Ethical approval}

The project was approved by the Danish Data Protection Agency (reference 2009-413471) and the Danish Health and Medicines Authority (reference 7-604-04-2/49/EHE). According to Danish law, approval from the ethical committee was not needed.

\section{Provenance}

Freely submitted; externally peer reviewed.

\section{Competing interests}

The authors have declared no competing interests.

\section{Open access}

This article is Open Access: CC BY-NC 3.0 license (http://creativecommons.org/ licenses/by-nc/3.0/).

\section{Acknowledgements}

The authors thank the participating GPs and patients for their contributions to this study and Andreas Schröder for delivering information from the FIP study.

\section{Discuss this article}

Contribute and read comments about this article: bjgp.org/letters a PCS of 43.5 and an MCS of 45.0.32 This variation seems to be related to different population mean ages; older populations tend to present lower scores, but may also be affected by different severities of disorders. The mean scores were consistently lower among BDS-positive patients than the mean scores in the general population for several (well defined) chronic conditions, such as diabetes mellitus $(\mathrm{PCS}=41.1$, MCS $=47.8),{ }^{31}$ osteoarthritis $(P C S=38.6$, MCS $=48.0),{ }^{31}$ and multiple sclerosis $(P C S=36.1, M C S=45.8) .33$ The results are in line with the results of Barsky et al, who found that patients with functional disorders tended to have a higher use of healthcare services than patients without functional disorders. ${ }^{34,35}$ The study also found that patients with BDS were more likely to receive pharmacological treatment with PPIs and opioids, although previous studies have shown that pharmacological treatment of patients with functional disorders has no discernible effect and that no organic findings occur in about 70\% of cases of dyspepsia. ${ }^{36-38}$ Excessive or unnecessary treatment may also hold a risk of causing iatrogenic harm to the patient. ${ }^{39}$

\section{Implications for research and practice}

Most of the patients with BDS reported to have self-perceived long-term physical illness, although the GP assessment for these particular patients did not include chronic physical disease. This disagreement between the GP's perception of disease and the patient's experience of illness may indicate that some patients with BDS lack a diagnosis and are not offered appropriate treatment.

Results from this study support the potential usefulness of BDS as a clinical diagnosis because it identifies a group of patients with poor mental and physical health. The BDS criteria may provide an improved and valid basis for future therapeutic trials and epidemiological studies in primary care. However, longitudinal studies are needed to evaluate predictors and risk indicators of BDS and to gain insight into the long-term prognosis of patients with BDS. 


\section{REFERENCES}

1. Hanel G, Henningsen P, Herzog W, et al. Depression, anxiety, and somatoform disorders: vague or distinct categories in primary care? Results from a large cross-sectional study. J Psychosom Res 2009; 67(3): 189-197.

2. Fink $P$, Rosendal $M$, Olesen $F$. Classification of somatization and functional somatic symptoms in primary care. Aust N Z J Psychiatry 2005; 39(9): 772-781.

3. Fink P, Toft T, Hansen MS, et al. Symptoms and syndromes of bodily distress: an exploratory study of 978 internal medical, neurological, and primary care patients. Psychosom Med 2007; 69(1): 30-39.

4. Olde Hartman T, Hassink-Franke L, Dowrick C, et al. Medically unexplained symptoms in family medicine: defining a research agenda. Proceedings from WONCA 2007. Fam Pract 2008; 25(4): 266-271.

5. Budtz-Lilly A, Fink P, Ørnbøl E, et al. A new questionniare to identify bodily distress in primary care: the 'BDS checklist'. J Psychosom Res 2015; 78(6): 536-545.

6. Fink P, Schröder A. One single diagnosis, bodily distress syndrome, succeeded to capture 10 diagnostic categories of functional somatic syndromes and somatoform disorders. J Psychosom Res 2010; 68(5): 415-426.

7. Lam TP, Goldberg DP, Dowell AC, et al. Proposed new diagnoses of anxious depression and bodily stress syndrome in ICD-11-PHC: an international focus group study. Fam Pract 2013; 30(1): 76-87.

8. Schröder A, Rehfeld E, Ornbøl E, et al. Cognitive-behavioural group treatment for a range of functional somatic syndromes: randomised trial. Br J Psychiatry 2012; 200(6): 499-507.

9. Rosendal M, Vedsted P, Christensen KS, Moth G. Psychological and social problems in primary care patients: general practitioners' assessment and classification. Scand J Prim Health Care 2013; 31(1): 43-49.

10. WONCA. International classification of primary care, revised 2nd edition (ICPC2-R). Oxford: Oxford University Press, 2005.

11. Ware J Jr, Kosinski M, Keller SD. A 12-Item Short-Form Health Survey: construction of scales and preliminary tests of reliability and validity. Med Care 1996; 34(3): 220-233.

12. Christensen KS, Fink $P$, Toft $T$, et al. A brief case-finding questionnaire for common mental disorders: the CMDQ. Fam Pract 2005; 22(4): 448-457.

13. Rosendal M, Christensen KS, Agersnap L, et al. Klinisk vejledning for almen praksis. Funktionelle lidelser. [Clinical guidelines for general practice. functional disorders.] Copenhagen: Dansk Selskab for Almen Praksis, 2013.

14. Pedersen CB. The Danish Civil Registration System. Scand J Public Health 2011; 39 (7 Suppl): 22-25.

15. Thygesen LC, Daasnes C, Thaulow I, Brønnum-Hansen H. Introduction to Danish (nationwide) registers on health and social issues: structure, access, legislation, and archiving. Scand J Public Health 2011; 39 (7 Suppl): 12-16.

16. Kildemoes HW, Sørensen HT, Hallas J. The Danish National Prescription Registry. Scand J Public Health 2011; 39 (7 Suppl): 38-41.

17. Lynge E, Sandegaard JL, Rebolj M. The Danish National Patient Register. Scand J Public Health 2011; 39 (7 Suppl): 30-33

18. Mors O, Perto GP, Mortensen PB. The Danish Psychiatric Central Research Register. Scand J Public Health 2011; 39 (7 Suppl): 54-57.

19. Andersen JS, Olivarius Nde F, Krasnik A. The Danish National Health Service Register. Scand J Public Health 2011; 39 (7 Suppl): 34-37.

20. Munk-Jørgensen P. Fink P, Brevik Jl, et al. Psychiatric morbidity in primary public health care: a multicentre investigation. Part II. Hidden morbidity and choice of treatment. Acta Psychiatr Scand 1997; 95(1): 6-12.

21. Peveler R, Kilkenny L, Kinmonth AL. Medically unexplained physical symptoms in primary care: a comparison of self-report screening questionnaires and clinical opinion. J Psychosom Res 1997; 42(3): 245-252.

22. Rosendal M, Bro F, Fink $P$, et al. Diagnosis of somatisation: effect of an educational intervention in a cluster randomised controlled trial. Br J Gen Pract 2003; 53(497): 917-922.

23. Toft T, Fink P, Oernboel E, et al. Mental disorders in primary care: prevalence and co-morbidity among disorders. Results from the functional illness in primary care (FIP) study. Psychol Med 2005; 35(8): 1175-1184.

24. Creed F, Barsky A. A systematic review of the epidemiology of somatisation disorder and hypochondriasis. J Psychosom Res 2004; 56(4): 391-408.

25. Mayou R, Kirmayer LJ, Simon G, et al. Somatoform disorders: time for a new approach in DSM-V. Am J Psychiatry 2005; 162(5): 847-855.

26. de Waal MW, Arnold IA, Eekhof JA, van Hemert AM. Somatoform disorders in general practice: prevalence, functional impairment and comorbidity with anxiety and depressive disorders. Br J Psychiatry 2004; 184: 470-476.

27. Deary V, Chalder T, Sharpe M. The cognitive behavioural model of medically unexplained symptoms: a theoretical and empirical review. Clin Psychol Rev 2007; 27(7): 781-797.

28. Lieb R, Meinlschmidt G, Araya R. Epidemiology of the association between somatoform disorders and anxiety and depressive disorders: an update. Psychosom Med 2007; 69(9): 860-863.

29. Löwe B, Spitzer RL, Williams JB, et al. Depression, anxiety and somatization in primary care: syndrome overlap and functional impairment. Gen Hosp Psychiatry 2008; 30(3): 191-199.

30. Jiao J, Vincent A, Cha SS, et al. Relation of age with symptom severity and quality of life in patients with fibromyalgia. Mayo Clin Proc 2014; 89(2): 199-206.

31. Nacul LC, Lacerda EM, Campion $P$, et al. The functional status and well being of people with myalgic encephalomyelitis/chronic fatigue syndrome and their carers. BMC Public Health 2011; 11: 402.

32. Spiegel BM, Gralnek IM, Bolus R, et al. Is a negative colonoscopy associated with reassurance or improved health-related quality of life in irritable bowel syndrome? Gastrointest Endosc 2005; 62(6): 892-899.

33. Dubayova T, Krokavcova M, Nagyova I, et al. Type D, anxiety and depression in association with quality of life in patients with Parkinson's disease and patients with multiple sclerosis. Qual Life Res 2013; 22(6): 1353-1360.

34. Barsky AJ, Ettner SL, Horsky J, Bates DW. Resource utilization of patients with hypochondriacal health anxiety and somatization. Med Care 2001; 39(7): 705-715

35. Barsky AJ, Orav EJ, Bates DW. Somatization increases medical utilization and costs independent of psychiatric and medical comorbidity. Arch Gen Psychiatry 2005; 62(8): 903-910

36. Kjeldsen HC. Dyspepsia in general practice. Aarhus: Faculty of Health Science, Aarhus University, 2005

37. Lassen A, Hallas J, Schaffalitzky De Muckadell OB. Use of anti-secretory medication: a population-based cohort study. Aliment Pharmacol Ther 2004 20(5): 577-583.

38. Forgacs I, Loganayagam A. Overprescribing proton pump inhibitors. BMJ 2008 336(7634): $2-3$.

39. Fink P. Surgery and medical treatment in persistent somatizing patients. $J$ Psychosom Res 1992; 36(5): 439-447. 


Appendix 1. The 25-item bodily distress syndrome checklist
During the last 4 weeks, have you been
bothered by ...
Cardiopulmonary/autonomic larousal) symptoms:
- Palpitations/heart pounding?
- Precordial discomfort?
- Breathlessness without exertion?

